\title{
ИННОВАЦИОННЫЕ ФАКТОРЫ КОНКУРЕНТОСПОСОБНОСТИ ПРОИЗВОДСТВЕННОГО ПОТЕНЦИАЛА ОСНОВНЫХ ОТРАСЛЕЙ ЖИВОТНОВОДЧЕСКОГО ПОДКОМПЛЕКСА
}

\author{
(c) 2021 Васильченко Марианна Яковлевна \\ кандидат экономических наук, старший научный сотрудник \\ Институт аграрных проблем Российской академии наук, Россия, Саратов \\ E-mail: mari.vasil4enko@yandex.ru
}

Повышение конкурентоспособности отраслей сельского хозяйства во многом зависит от технологического уровня производственного потенциала и эффективности использования ресурсов. В настоящее время осуществляется переход российской экономики на новую технологическую парадигму, однако по темпам внедрения технологий нового поколения сельское хозяйство значительно отстает от других отраслей экономики.

В статье разработаны методические походы к определению ключевых факторов роста конкурентоспособности производственного потенциала отраслей животноводческого подкомплекса. Приращение знаний достигнуто за счет комплексного исследования технологических факторов на основе разработанной матрицы факторов эффективности производственного потенциала животноводческого подкомплекса с выделением инновационного профиля продукции, ресурсов и средств государственной поддержки. Состояние конкурентоспособности производственного потенциала основных подотраслей животноводства выявлялось на основе балльной системы оценки уровня инновационности ресурсных, производственных и институциональных компонент с использованием соответствующих индикаторов.

Ключевые слова: агропромышленный комплекс, животноводство, конкурентоспособность, инновационные факторы конкурентоспособности, государственная поддержка

Введение

Прогноз научно-технологического развития российского агропромышленного комплекса на период до 2030 года предполагает реализацию двух сценариев: локальный рост и глобальный прорыв, строящихся на разнообразных моделях и направлениях. В случае реализации сценария «Локальный рост» прирост животноводческой продукции в 2025-2030 гг. составит по говядине $-0,6 \%$; свинине $-4,2 \%$; мясу птицы $-5,3 \%$. Сценарий «Глобальный прорыв» предусматривает более высокие темпы прироста за счет внедрения принципиально новых технологий (генетика, новые кормовые добавки: говядина$0,9 \%$; свинина $-5,2 \%$; мясо птицы $-6,3 \%$. Объем производства свинины при этом сценарии составит в 2030 г. 17,6\%, а мяса птицы - 18,5\% общего объема производства сельскохозяйственной продукции.

Роль инновационных факторов в повышении конкурентоспособности отраслей и отдельных секторов экономики как на внутреннем, так и на мировом рынках продовольствия достаточно широко исследована в теоретико-методологическом и практическом аспектах. Общепризнано, что инновационноинвестиционные факторы являются ключевым условием модернизации российской экономики и ее продовольственного сектора [7]. Так, в исследованиях А. Тихомирова и Н.А. Морозова выявлены основные тенденции технологического развития, подтвержденные показателями уровня обновления материально-технической базы животноводства и кормопроизводства, а также расхода отдельных видов ресурсов на производство животноводческой продукции [9,4]. Растет востребованность научно-технологических решений, учитывающих особенности региональной специализации сельского хозяйства и агроклиматические условия.

В настоящее время осуществляется переход к новой технологической парадигме, включающей биотехнологии, точное сельское хозяйство, роботизацию производственных процессов, платформенные технологии межотраслевого назначения, а также когнитивные технологии и технологии урбанизированного сельского хозяйства [6]. Однако по темпам внедрения тено- 
логий нового поколения, в том числе и цифровых, сельское хозяйство значительно отстает от других отраслей экономики.

Высокий потенциал внедрения цифровых технологий в животноводстве и кормопроизводстве имеют лишь крупные экспортоориентированные хозяйства. Следует отметить, что проблемы низкого уровня технологического развития мелкотоварного сельского хозяйства актуальны и для ряда восточно-европейских стран, на что обращает внимание в своих исследованиях Agatha Popescu [12].

Результаты исследования. Конкурентоспособность отраслей сельского хозяйства во многом зависит от технологического уровня производственного потенциала и эффективности использования ресурсов. В 2014-2018 гг. степень износа основных фондов: по виду экономической деятельности «Растениеводство и животноводство, охота и предоставление соответствующих в этих областях» составляла $39 \%-41,8 \%$, что было несколько ниже, чем по экономике в целом $(47,3-49,4 \%)$ и было связано с происходящими процессами технологической модернизации преимущественно в секторах животноводства. В сравнительно короткий период сформировался промышленный сектор свиноводства: с 2010 по 2018 гг. доля животных, перерабатываемых на новых и модернизированных предприятиях, возросла с $12 \%$ до 58\%; к 2022 г. доля промышленного сектора в подотрасли должна превысить
75\% [8]. Уровень модернизации в молочном скотоводстве существенно ниже, что подтверждается следующими данными: лишь 40-50\% предприятий, занятых производством молока, и 60-70\% перерабатывающих предприятий соответствуют современным стандартам. Основным барьером для распространения инноваций является сложившаяся институциональная структура молочного подкомплекса с высокой долей мелкотоварного сектора и локализацией предприятий по углубленной переработке молока, что особенно заметно в процессе исследований региональных различий данного сегмента агропромышленного комплекса. Ключевым условием дальнейшего роста конкурентоспособности животноводческого сектора остается преодоление научно-технологического отставания отечественного АПК от уровня ведущих зарубежных стран и снижение его зависимости от импорта машин, техники и оборудования. Фактические и прогнозные показатели ресурсоемкости производства свинины, достижение которых может быть осуществлено в результате использования инновационных кормовых и генетических ресурсов с одновременным замещением валютозависимых компонент затрат, представлены на рис. 1.

Исследования специалистов Национального союза свиноводов определяют границу безубыточности предприятий при уровне конверсии корма 2,8 ц к ед. В 2019 г. лишь в отдельных рос-

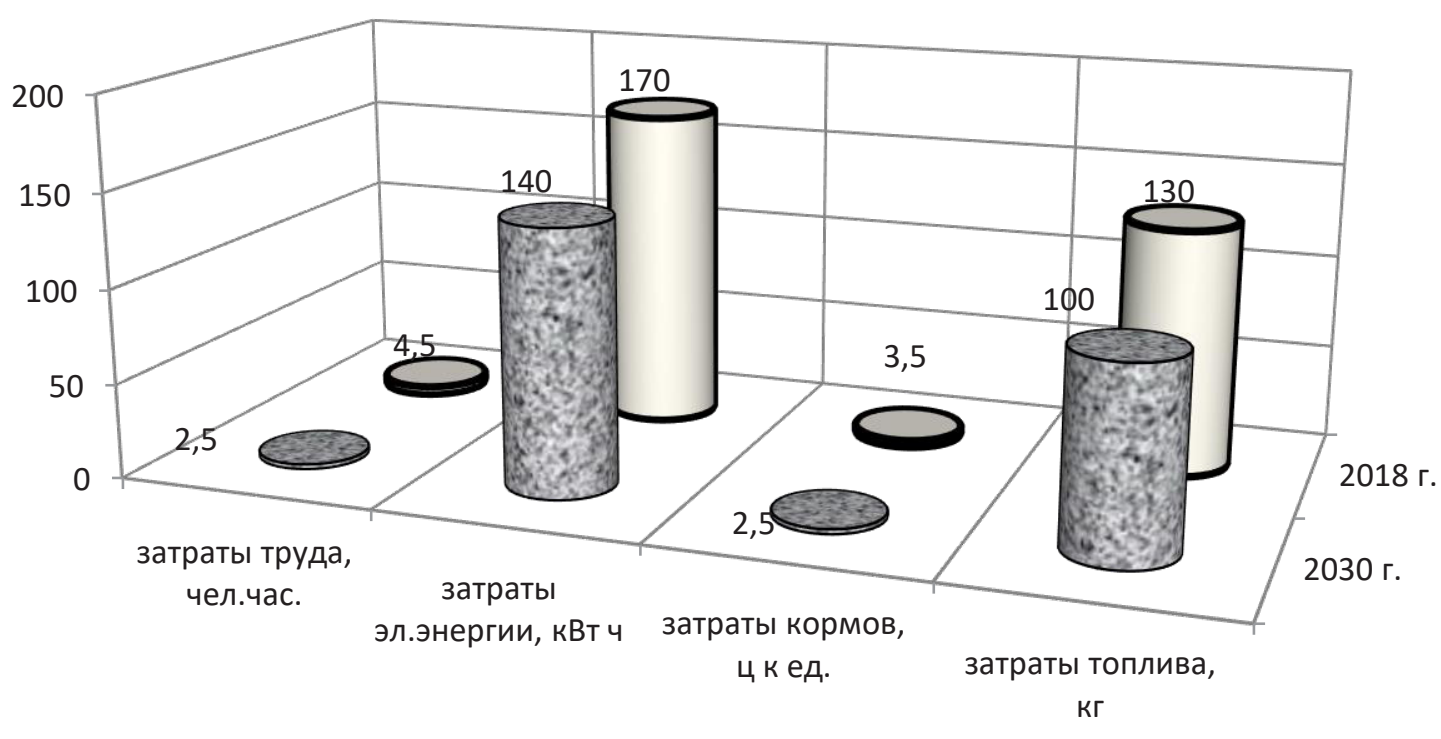

a 2030 г. $\$ 2018$ г.

Рисунок 1. Фактические и прогнозные показатели ресурсоемкости производства свинины в России (в расчете на 1 ц продукции) [6,10] 
сийских компаниях из числа пятидесяти крупнейших расход кормов составлял 2,5-2,7 ц к.ед, а выход мяса в расчете на свиноматку - свыше 3,5 т в живом весе. Более полное использование инновационных генетических ресурсов позволяет получать выход мяса от 3,0 т до 4 т [3].

Комплексное исследование технологических факторов конкурентоспособности осуществлялось на основе разработанной матрицы инновационных факторов эффективности производственного потенциала животноводческих подотраслей с выделением инновационного профиля продукции, ресурсов и средств государственной поддержки (таблица 1).
Важнейшим направлением государственной агропродовольственной политики является формирование конкурентоспособной отечественной племенной базы животноводства. Согласно данным Всероссийской сельскохозяйственной переписи 2016 года, наибольшая доля племенного скота в сельскохозяйственных организациях (без учета малых предприятий) была сосредоточена в молочном (38,6\%) и мясном скотоводстве (36,1\%).

В то же время в молочном скотоводстве России сохраняется достаточно высокая доля импорта племенных ресурсов, тогда как потребности мясного скотоводства обеспечиваются

Таблица 1. Матрица инновационных факторов эффективности производственного потенциала животноводческих подотраслей России (2018-2019 гг.)

\begin{tabular}{|c|c|c|c|c|}
\hline Инновационые факторы & $\begin{array}{c}\text { Молочное } \\
\text { скотоводство }\end{array}$ & Свиноводство & Птицеводство & $\begin{array}{c}\text { Мясное } \\
\text { скотоводство }\end{array}$ \\
\hline \multicolumn{5}{|c|}{ Ресурсные компоненты } \\
\hline $\begin{array}{l}\text { Удельный вес племенных животных } \\
\text { в СХО, не относящихся к субъектам } \\
\text { малого предпринимательства, \% [2] }\end{array}$ & 38,6 & 4,0 & 11,2 & 36,1 \\
\hline Импорт племенных ресурсов, \% & $43-44$ & 80 & $95-98$ & $8-10$ \\
\hline $\begin{array}{l}\text { Соответствие предприятий совре- } \\
\text { менным технологическим стандар- } \\
\text { там, \% }\end{array}$ & $\begin{array}{c}\text { производство } \\
\text { молока - 40-50; } \\
\text { переработка } \\
\text { молока }-50-60\end{array}$ & $85-90$ & 65 & 60 \\
\hline $\begin{array}{l}\text { Сбалансированность по комбикор- } \\
\text { мам, \% }\end{array}$ & 50 & 58 & 92 & 42 \\
\hline $\begin{array}{l}\text { Уровень инновационности затрат } \\
\text { кормов, \% }\end{array}$ & 70 & 92 & 90 & 80 \\
\hline $\begin{array}{l}\text { Уровень инновационности затрат } \\
\text { труда, \% }\end{array}$ & $30-40$ & $55-60$ & $65-70$ & 40 \\
\hline $\begin{array}{l}\text { Уровень инновационности затрат } \\
\text { электроэнергии, \% }\end{array}$ & $85-90$ & 80 & 78 & 40 \\
\hline $\begin{array}{l}\text { Уровень инновационности затрат } \\
\text { топлива, \% }\end{array}$ & 35 & 77 & 65 & 35 \\
\hline \multicolumn{5}{|c|}{ Производственные компоненты } \\
\hline $\begin{array}{l}\text { Соответствие показателей продук- } \\
\text { тивности инновационным параме- } \\
\text { трам, \% }\end{array}$ & 66 & 80 & 80 & 75 \\
\hline $\begin{array}{l}\text { Удельный вес затрат на технологи- } \\
\text { ческие инновации в отгруженных } \\
\text { товарах, \% }\end{array}$ & 0,7 & 0,3 & 1,2 & 0,6 \\
\hline $\begin{array}{l}\text { Удельный вес инновационных това- } \\
\text { ров в отгруженной продукции, \% }\end{array}$ & 1 & 3,1 & 4,7 & 1 \\
\hline \multicolumn{5}{|c|}{ Институциональные компоненты } \\
\hline $\begin{array}{l}\text { 1.Степень достаточности инстру- } \\
\text { ментов поддержки инновационного } \\
\text { развития }\end{array}$ & низкая & средняя & средняя & $\begin{array}{c}\text { относительно } \\
\text { высокая }\end{array}$ \\
\hline $\begin{array}{l}\text { 2.Степень доступности инструмен- } \\
\text { тов инновационной поддержки }\end{array}$ & низкая & средняя & средняя & средняя \\
\hline $\begin{array}{l}\text { 3. Степень охвата мерами иннова- } \\
\text { ционной поддержки }\end{array}$ & низкая & средняя & средняя & $\begin{array}{c}\text { относительно } \\
\text { высокая }\end{array}$ \\
\hline
\end{tabular}


преимущественно собственными племенными ресурсами. Птицеводческая подотрасль на 90\% зависит от импортного племенного материала.. Создание отечественного кросса мясных кур позволит снизить зависимость птицеводства от импорта на 25-30\%.

Соответствие предприятий современным технологическим стандартам в большей степени характерно для промышленного свиноводства (85-90\%); тогда как в остальных подотраслях этот показатель значительно ниже. Так, по данным Росптицесоюза, производство около 65\% мяса птицы осуществляется на птицефабриках, отвечающих современным технологическим стандартам.

Уровень инновационности остальных ресурсных компонент - кормов, труда, электроэнергии и топлива определялся на основе нормирования фактических показателей ресурсоемкости по отношению к пороговым, достижение которых во многом зависит от темпов технико-технологической модернизации, улучшения условий содержания скота и птицы, кормовой сбалансированности по энергии, белку, минеральным добавкам, витаминам [5]. Например, в молочном скотоводстве внедрение новых систем машин приведет к уменьшению затрат труда в 2,5-3 раза; электроэнергии - на 10-20\%; жидкого топлива - в 3-4 раза; кормов - на 10$20 \%[4]$.

Институциональные компоненты отражают недостаточный уровень стимулирования и поддержки технологической модернизации, а также распространения и внедрения инноваций. В молочном животноводстве большинство хозяйств имеют ограниченный доступ к средствам поддержки; исследованиями выявлены существенные межрегиональные различия в использовании затрат на поддержку племенного крупного рогатого скота молочного направления и возмещении затрат на модернизацию объектов молочного скотоводства [1]. Для свиноводческих предприятий достаточно актуальным является увеличение лимита по льготным краткосрочным кредитам; возобновление выдачи кредитов на закупку зерна для производства комбикормов. Для птицеводства дальнейшее совершенствование механизмов поддержки технологического развития связано с предоставлением льготных инвестиционных кредитов на реконструкцию и модернизацию птицеводческих предприятий и племенных репродукторов. В 2022 году в птице- водстве предусматривается возмещение капитальных затрат на строительство и модернизацию объектов по производству инкубационного яйца.

Дальнейшее совершенствование механизмов стимулирования инновационного развития АПК и его отраслей связано с созданием технологических платформ, совершенствованием нормативно-правовой и финансовой поддержки [11].

Разработанные методические походы к оценке конкурентоспособности производственного потенциала основных подотраслей животноводства основываются на балльной системе оценки уровня инновационности ресурсных, производственных и институциональных компонент, а также механизмов стимулирования технологического развития с использованием соответствующих индикаторов.

Оценка проводилась по десятибалльной системе, причем значение каждого балла определялось на основе нормированного уровня инновационности ресурсных и производственных компонент, приведенного к значениям нормативных, прогнозных или целевых индикаторов. При расчете баллов по производственным компонентам с использованием статистики о затратах на технологические инновации и инновационной продукции в качестве базы использовались максимальные значения по регионам.

Уровень инновационности для институциональных компонент оценивался по критериям эффективности механизмов стимулирования технологического развития и степени полноты применяемых инструментов.

Результаты оценки уровня инновационности производственного потенциала представлены в таблице 2.

Предложенные методические подходы к выявлению основных факторов повышения конкурентоспособности производственного потенциала отраслей животноводческого подкомплекса основываются на использовании инновационного профиля ресурсов, продукции и средств государственной поддержки. Оценка уровня инновационности ресурсных, производственных и институциональных компонент позволяет охарактеризовать состояние конкурентоспособности производственного потенциала животноводства и обосновывать меры по совершенствованию механизмов стимулирования инновационного развития. 
Таблица 2. Оценка уровня инновационности производственного потенциала животноводческих подотраслей, баллов

\begin{tabular}{|l|c|c|c|c|}
\hline \multicolumn{1}{|c|}{ Инновационные факторы } & $\begin{array}{c}\text { Молочное } \\
\text { скотоводство }\end{array}$ & Свиноводство & Птицеводство & $\begin{array}{c}\text { Мясное } \\
\text { скотоводство }\end{array}$ \\
\hline Ресурсные компоненты & 44 & 49 & 48 & 43 \\
\hline Производственные компоненты & 12 & 10 & 12 & 13 \\
\hline Институциональные компоненты & 9 & 18 & 17 & 24 \\
\hline Итого & 65 & 77 & 77 & 80 \\
\hline
\end{tabular}

\section{Библиографический список}

1. Васильченко М.Я. Инструменты поддержки процесса распространения инноваций в отраслях АПК (на примере молочного скотоводства) //Региональные агросистемы: экономика и социология: экономика и социология: [Электронный ресурс].-Саратов: ИАгП РАН, 2019. № 3.- URL: http://iagpran.ru/journal.php?id.

2. Итоги Всероссийской сельскохозяйственной переписи 2016 года: В 8 т./Федеральная служба гос. статистики. М.: ИИЦ «Статистика России», 2018. Т. 1: Основные итоги Всероссийской сельскохозяйственной переписи 2016 года по Российской Федерации._- URL: www.gks.ru/free_doc/new_site/ siness/sx/vsxp2016/VSHP_2016_ T1_k1.pdf

3. Ковалев Ю.И. Реальный риск перенасыщения рынка свинины в 2020-2025 году: предпосылки, вызовы, возможности.- URL: https://veterina.ru/wp-content/uploads/2020/12/1.1.-Kovalev-YUI-Svinovodstvo-2020END.pdf.

4. Морозов Н. М. Морозов И. Ю. Система машин для животноводства и направления технического прогресса в отрасли // Техника и технологии в животноводстве и направления технического прогресса в отрасли. 2020. № 1 (37). С. 4-13.

5. Потапов А.П. Использование таблиц «затраты-выпуск» в исследованиях динамики и структуры ресурсоемкости аграрного производства // Проблемы прогнозирования. 2019. № 2. С. 87-97.

6. Прогноз научно-технологического развития агропромышленного комплекса Российской Федерации на период до 2030 года / Минсельхоз России; Нац. исслед. ун-т «Высшая школа экономики».- М.: НИУ ВшЭ, 2017. - 140 c.

7. Рау В.В., Скульская Л.В., Широкова Т. К. Тенденции и факторы изменения ресурсоемкости аграрного сектора // Проблемы прогнозирования. 2013. № 4 (139). С. 55-66.

8. Российский мясной рынок: текущее состояние и перспективы до 2024 года.- URL: https://animal-profi.ru/ upload/iblock/342/342e2463043a4407b1b532b5a122a6d8.pdf

9. Тихомиров А. Технологическая модернизация животноводства: современное состояние и экономические факторы развития //АПК: экономика, управление. 2018. № 4. С. 42-51.

10. Цой Л. М. Влияние удельных затрат ресурсов на себестоимость производства свинины // Вестник ВНИИМЖ. 2018. № 1(29). С. 50-53.

11. Derunova E., Vasilchenko M., ShabanovV., Derunov V. Mechanisms to stimulate the acceleration of innovative development in the agroindustrial complex //Scientific Papers Series Management, Economic Engineering in Agriculture and Rural Development. 2021. Vol. 21, Issue 2, P.209-222.

12. Popescu A. The Development of Agricultural Production in Romania in the Period 2010-2019 - a Statistical Approach //Annals of the Academy of Romanian Scientists Series on Agriculture, Silviculture and Veterinary Medicine Sciences. 2021. Vol.10, N.1. P. 107-123. 